Research Article

\title{
Primary closure after common bile duct exploration versus T-tube drainage: a prospective randomized study and review of literature
}

\author{
Arun Kumar Rathore, Rajesh Gupta*, Kunwar Vishal, \\ Joginder Pal Singh Shakya, Shwetank Prakash
}

Department of Surgery, S N Medical College, Agra, Uttar Pradesh, India

Received: 12 March 2016

Revised: 12 April 2016

Accepted: 03 June 2016

*Correspondence:

Dr. Rajesh Gupta,

E-mail: rkg04@rediffmail.com

Copyright: () the author(s), publisher and licensee Medip Academy. This is an open-access article distributed under the terms of the Creative Commons Attribution Non-Commercial License, which permits unrestricted non-commercial use, distribution, and reproduction in any medium, provided the original work is properly cited.

\begin{abstract}
Background: $\mathrm{T}$ tube drainage following CBD exploration has been a gold standard for a long time now. This has its own set of problems, mainly prolonging hospital stay and leakage around T-tube. This study was designed to assess the outcome of primary repair of $\mathrm{CBD}$ in terms of operating time, duration of hospital stay and postoperative complications.

Methods: We conducted a prospective randomized study of 60 patients divided into two groups, at our institute to see the effectiveness of primary closure and compared the results with those patients who had T tube drainage.

Results: Our results indicate that the hospital stay is reduced to half in cases with primary closure and there were no significant complications resulted in primary closure cases.

Conclusions: Primary closure of the common bile duct following CBD exploration is a safe and effective method and it helps to reduce the morbidity related to T-tube use. We strongly recommend the primary closure of CBD following its exploration.
\end{abstract}

Keywords: CBD, T-tube, Primary closure, Choledocholithiasis

\section{INTRODUCTION}

Gallstone disease occurs in 3\%-20\% of the population worldwide. Gall bladder, common bile duct, common hepatic duct, or right or left hepatic ducts are sites where gall stones may occur. CBD stones i.e choledocholithiasis develop in about $15 \%$ of people with gallstone and surgical intervention is necessary for this common problem. There are two management options. ${ }^{1}$ In case of smaller stones endoscopic retrograde cholangiopancreatography (ERCP) is suggested and surgery is required in case of larger stones or when ERCP fails. Surgical exploration of CBD i.e choledochotomy may be done either open or by laparoscopically. After the CBD exploration, stones are removed and traditionally, common bile duct (CBD) is closed over T-tube. The purpose of using $\mathrm{T}$-tube drainage after open CBD explorationare post-operative drainage of common the bile duct to reduce edemaand intra luminal pressure of CBD to visualize and extract retained bile duct stones. ${ }^{2}$ But a number of potential complications exists with this therapeutic modality. ${ }^{3}$ These include bacteremia, dislodgement of tube, obstruction and/or fracture of tube. ${ }^{4}$ Furthermore, leakage of bile may be encountered after removal. ${ }^{5}$ Patient may have to carry it for several weeks before removal. ${ }^{6}$ All of these lead to prolong length of hospital stay. ${ }^{7}$ It also causes psychological trauma to the patient along with increases bed occupancy, hospital 
patient load and thus economic burden to the country. Currently, primary closure of CBD has been described in literature to overcome these adverse consequences of $\mathrm{T}$ tube. ${ }^{8,9}$ Although it was thought that T-tube has definitive role after CBD clearance, some authors found no significant difference in the morbidity or mortality between primary closure and T-tube drainage. ${ }^{10,11}$ Others found higher morbidity in terms of more biliary infection, discomfort from tube, delayed hospital discharge. ${ }^{12-18}$

This study was designed to assess the outcome of primary repair of $\mathrm{CBD}$ in terms of operating time, duration of hospital stay and postoperative complications.

\section{METHODS}

This was a prospective study conducted from July 2014 to December 2015 in department of surgery, Sarojini Naidu Medical College Agra. A total of 60 patients having palpable stones in the $\mathrm{CBD}$, preoperative radiographic demonstration of choledocholithiasis, positive intraoperative cholangiogram, and dilated CBD were explored for $\mathrm{CBD}$ stones with baseline investigations which includes blood $\mathrm{R} / \mathrm{E}$, renal function tests, X-ray chest (P/A), ECG, Serum bilirubin, Serum alkaline phosphatase,

SGPT, SGOT, and ultrasonography upper abdomen. To rule out malignancy contrast enhanced computerized tomography was done in selected cases. Patients with malignancy, renal failure, pancreatic pathology causing jaundice and other severe co-morbidities were excluded from study. The patients were divided into two groups on the basis of management group A-CBD exploration with primary closure and group B-CBD exploration with insertion of T-tube. All selected patients underwent a cholecystectomy followed by choledochotomy. Then the stones were removed and CBD was flushedwith normal saline ensuring no distal obstruction. Primary closure was done in $30(50 \%)$ cases where $\mathrm{T}$ tube drainage was givenin $30(50 \%)$ cases. Primary closure of CBD was done with continuous or interrupted suture of No. 3-0 or No. 4-0 vicryl on an atraumatic needle. A subhepatic drain was kept 48 hours. For T-tube drainage No. $12 \mathrm{~F}$ gauge T-tube was used. T-tube was removed on $14^{\text {th }}$ postoperative day after satisfactory post-operative cholangiography. All patients were given pre-operative and post-operative care along with antibiotics and follow up was taken for next 3 months.

\section{RESULTS}

Out of 60 patients, $46(76 \%)$ were females and $14(24 \%)$ males. The maximum number of patients was found to be in the age group 30-59 years among total range of age 2069 years with mean age 43.7 years. In group A, the average duration of hospital stay was 8.2 days (ranging 515 days) and in group B, the average hospital stay was 15.7 days ranging from 8-25 days. These values were statistically significant. In group A, one case (3.3\%) developed biliary leakage which was managed by keepingsub-hepatic drain for 5 days, two patients $(6.7 \%)$ developed wound infection. In group B, two (6.7\%) patients had residual stones in the T-tube cholangiogram which was managed by saline irrigation via $\mathrm{T}$-tube for three days under antibiotic cover and two patients (6.7\%) developed wound infection. The infection was superficial in all cases and treated by antibiotics and local dressing. No patient in the study developed cholangitis, postoperative hemorrhage, biliary peritonitis, sub-phrenic abscess, acute pancreatitis, intestinal obstruction and post- operative jaundice in either of the group. There was no mortality in this study (Table 1).

Table 1: Hospital stay and postoperative complications in the 2 groups.

\begin{tabular}{|lll|}
\hline & $\begin{array}{l}\text { Group - A } \\
(\mathbf{n = 3 0})\end{array}$ & $\begin{array}{l}\text { Group - B } \\
(\mathbf{n = 3 0})\end{array}$ \\
\hline Hospital stay & $8.2(5-15)$ days & $15.7(8-25)$ days \\
\hline Biliary leakage & $1(3.3 \%)$ & 0 \\
\hline Wound infection & $2(6.7 \%)$ & $2(6.7 \%)$ \\
\hline Residual stone & 0 & $2(6.7 \%)$ \\
\hline
\end{tabular}

\section{DISCUSSION}

In the modern 'minimally invasive approach' era, the current standard protocol for the treatment of CBD stones is to clear and drain the CBD by ERCP, followed by laparoscopic cholecystectomy. However, these minimally invasive approaches are not widely practiced in many developing countries due to the lack of equipment and trained endoscopists. Even in the developed world, in rural settings, there is lack of equipment for these techniques Ahmad et al. As suggested by a Cochrane database review published in 2006 ERCP was less successful than open surgery in CBD stone clearance and was associated with a higher mortality Kharbutli et al. There is also an increased recurrence rate of CBD stones following endoscopic removal Gurusamy $\mathrm{KS}$ et al. Traditionally, exploration of the CBD has been done by the placement of a T-tube. The T-tube drainage is helpful to prevent bile stasis, decompress the biliary tree, and minimize the risk of bile leakage. A T-tube has also provided an easy percutaneous access for cholangiography and extraction of retained stones. Despite these potential advantages, morbidity rates related to $\mathrm{T}$-tube presence have been reported to be at a rate of $4 \%$ to $16.4 \%$. The $\mathrm{T}$ tube-related complications include accidental $\mathrm{T}$-tube displacement leading to CBD obstruction, bile leakage, persistent biliary fistulas, and excoriation of the skin, cholangitis from exogenous sources through the T-tube, and dehydration and saline depletion. ${ }^{19,20}$ Additionally, CBD stenosis has been reported as a long term complication after T-tube removal. After discharge, in dwelling T-tubes become uncomfortable, requiring continuous management, thus restricting patient's activity because of the risk of dislodgement. Regardless of the technique, the practice of using T-tubes versus primary closure of the bile duct is a 
subject of discussion, now days the trend is towards primary closure Isla AM et al. Many authors have advocated primary Khaled Ahmed El- Dabee et al closure of the CBD following stone removal Wills VL et al. Primary closure without a T-tube is safe and associated with a lower complication rate Cuschieri et al. The four requirements for a safe and successful primary closure of common bile duct are patent Vater's ampulla, complete removal of all intra-ductal calculi, absence of pancreatic pathology and meticulous suture of the duct. ${ }^{21,22}$ This randomized and prospective study shows that hospital stay in the T-tube group ( 5 - 15 in primary group versus 8 - 25 in T-tube) was longer than primary closure group which is in agreement with studies conducted by Zhang et al, Ambreen et al and Kyoun Tah Noe et al. ${ }^{23-25}$ In our study In T-tube group, wound infections, biliary fistula around T-tube were more common. The main drawback of T-tube was that it was uncomfortable, require continuous management, and it restricts the patient's activity because of risk of dislodgement. ${ }^{26}$ It also affects the patient's life quality. ${ }^{27}$ Retained stones following CBD exploration remained a significant complication and it was reported in up to $10 \%$ of cases in relevant studies. ${ }^{28}$ In our study in T-tube group, two patient $(6.7 \%)$ reported with the retained stones during cholangiography and it was removed through the sinus tract of the T-tube using the saline irrigation. In primary closure group, the postoperative hospital stay was shorter, and the hospital expenses were also lower than in the T-tube group. It has no effect on patient's life quality after discharge from hospital. The use of primary closure was limited in the treatment of patients with severe acute biliary pancreatitis, acute pyogenic cholangitis, or ampullary stenosis because they required CBD decompression and drainage or other preferable therapeutic options. A CBD diameter that was too small $(<8 \mathrm{~mm})$ might be a contraindication for primary closure because smaller diameter might increase the risk of bile duct stricture. ${ }^{29}$ The authors agree with Decker et al that hospital stay is not a major criterion for assessing the outcome of surgery because discharge policies differ among institutions. Over the period of time, T-tube drainage was used less frequently as the approach changed from routine to a very selective use. To minimize postoperative complications, the indications for T-tube must be strictly followed, such as CBD stones secondary to intrahepatic duct stones or if there is undefined residual stone in the intrahepatic or extra hepatic ducts on intraoperative choledochoscopy; vague patency of the Oddi's Sphincter or failure to pass choledochoscope and Bakes dilator through Vater's ampulla due to edema or obstructed stones; acute suppurative cholangitis with severe edema of the CBD wall. According to the results of this early experience, primary closure did not increase the risk of bile leakage after the operation. Post-operative hospital stay and operation time were shorter and the hospital expenses were lower. Additionally, with primary closure, we could definitely avoid T-tube-related complications. Therefore, we can conclude that primary closure without external drainage after choledochotomy is feasible, safe, and cost- effective. Postoperative primary closure should be preferred in most cases after CBD exploration. However, randomized trials on a larger scale of patients and with a longer follow-up are necessary to address the issue of stenosis and other issues after primary closure.

\section{CONCLUSION}

Primary closure of the common bile duct appeared a safe and effective method and it helps to reduce the morbidity related to T-tube use. It reduces the hospital stay and overall cost and it can be done in most of the cases. However, randomized trials on a larger scale of patients and with a longer follow-up are necessary to address the issue of stenosis and other issues after primary closure.

\section{Funding: No funding sources Conflict of interest: None declared \\ Ethical approval: None required}

\section{REFERENCES}

1. Ahmed I, Pradhan C, Beckingham IJ, Brooks AJ, Rowlands BJ, Lobo DN. Is a T-tube necessary after common bile duct exploration? World J Surg. 2008;32:1485-8.

2. Lygidakis NJ. Hazards following T-tube removal after choledochotomy. Surg Gynecol Obstet. 1986;163:153-5.

3. Alhamdani A, Mahmud S, Jameel M, Baker A. Primary closure of choledochotomy after emergency laparoscopic common bile duct exploration. Surg Endosc. 2011;22:2190-5.

4. Ambreen M, Shaikh AR, Jamal A, Qureishi JN, Dalwani AG, Memon MM. Primary closure versus T-tube drainage after open choledochotomy. Asian J Surg. 2009;32:21-5.

5. Boerma D, Schwartz MP. Gallstone disease. Management of common bile-duct stones and associated gallbladder stones: surgical aspects. Best Pract Res Clin Gastroenterol. 2009;20:1103-16.

6. Cuschieri A, Lezoche E, Mornino M, Croce E, Lacy A, Tooulo J, et al. EAES multi-center prospective randomized trial comparing two stage versus singlestage management of patients with gallstone disease and ductal calculi. Surgical Endoscopy. 2009; 13(10):952.

7. Gurusamy KS, Samraj K. Primary closure versus Ttube drainage after laparoscopic common bile duct exploration. Cochrane Database Syst Rev. 2013;(6):CD005641.

8. Ahmad I, Pradhan C, Beckingham I, Brooks J, Rowlands BJ, Lobo DN. Is a T-tube necessary after common bile duct exploration? World J Surg. 2008;32:1485-8.

9. Isla AM, Griniatsos J, Karvounis E, Arbuckle JD. Advantages of laparoscopic stented choledochorrhaphy over T-tube placement. The British Journal of Surgery. 2009;91(7):862-6. 
10. Payne RA, Woods WG. Primary suture or T-tube drainage after Choledochotomy. Ann R Coll Surg Engl. 1986;68:196-8.

11. Halstead WS. Contributions to surgery of the bile passages, especially of the common bile duct. Bull Johns Hopkins Hosp. 1990;106:1-11.

12. Seale AK, Ledet WP. Primary common bile duct closure. Arch Surg. 1999;134:22-4.

13. Collin PG, Redwood C, Wynne-Jones J. Common bile duct without intra ductal drainage following choledochotomy. Br J Surg. 1960;47:661-7.

14. Sawyers JL, Herrington JL, Edwards WH. Primary closure of the CBD. Am J Surg. 1965;09:107-12.

15. Collin PG. Further experience with common bile duct suture without intra-ductal drainage following choledochotomy. BrJ Surg. 1967;54:854-6.

16. Keighley MBR, Burdon DW, Baddeley RM, Dorricott NJ, Oates GD, Watts GT, et al. Complication of supra duodenal choledochotomy: a comparison of three methods of management. $\mathrm{Br} \mathrm{J}$ Surg. 1976;63:754-8.

17. Vassilakis JS, Chattopadhyay DK, Irvin TT, Duthie HL. Primary closure of common bile duct after elective choledochotomy. J R Coll Surg Edinb. 1979;24:156-8.

18. Mirizzi PL. Primary suture of the common bile duct incholedocholithiasis. Arch Surg. 1942;44:44-54.

19. Cai H, Sun D, Sun Y, Bai J, Zhao H, Miao Y. Primary closure following laparoscopic common bile duct exploration combined with intraoperative cholangiography and choledochoscopy. World J Surg. 2012;36:164-70.

20. Wills VL, Gibson K, Karihaloot C, Jorgensen JO. Complications of biliary T-tubes after choledochotomy. ANZ J Surg. 2002;72:177-80.
21. Rafailidis S, Ballas K, Symeonidis N, Pavlidis T, Psarras K, Marakis H. Primary closure of common bile duct long-term results. Arch ISPUB. 2010;23:80-6.

22. Haider J, Aziz A, Khan L, Alam SN. Primary closure of common bile duct after open choledochotomy. J Surg Pak. 2009;14:173-5.

23. Leida Z, Ping B, Shuguang W, Yu H. A randomized comparison of primary closure and T-tube drainage of the common bile duct after laparoscopic choledochotomy. Surg Endosc. 2008;22:1595-600.

24. Ambreen M, Shaikh AR, Jamal A, Qureshi JN, Dalwani AG, Memon MM. Primary closure versus T-tube drainage after open choledochotomy. Asian J Surg. 2009;32:21-5.

25. Noh KT, Min SK, Lee HK. Comparison of primary closure and T-tube drainage following laparoscopic CBD exploration. J Korean Surg Soc. 2009;77:399403.

26. Ahmed I, Pradhan C, Beckingham IJ, Brooks AJ, Rowlands BJ, Lobo DN. Is a T-tube necessary after common bile duct exploration. J Surg. 2008;32:1485-8.

27. Zhang WJ, Xu GF, Wu GZ, Li JM, Dong ZT, Mo XD. Laparoscopic exploration of common bile duct with primary closure versus T-tube drainage: a randomized clinical trial. J Surg Res. 2009;157:e1e5.

28. Tan KK, Shelat VG, Liau KH, Chan CY, Ho CK. Laparoscopic common bile duct exploration: our first 50 cases. Ann Acad Med Singapore. 2010;39:136-42.

29. Tang CN, Tsui KK, Ha JP, Siu WT, Li MK. Laparoscopic exploration of the common bile duct: 10-year experience of 174 patients from a single centre. Hong Kong Med J. 2006;12:191-6.

Cite this article as: Rathore AK, Gupta R, Vishal K, Shakya JPS, Prakash S. Primary closure after common bile duct exploration versus T-tube drainage: a prospective randomized study and review of literature. Int Surg J 2016;3:1368-71. 